\title{
The Model of Family Counseling in Early Intervention Setting for Children with Special Needs
}

\author{
Sunardi \\ Universitas Pendidikan Indonesia, Indonesia \\ E-mail: nardilembang@upi.edu
}

\begin{abstract}
The aim of this research is to formulate the model of the family counseling for children with special needs by making parenting stress as a major successful indicator. This research is conducted by qualitative approach through studying the cases deeply in Laboratory of Special Education Department, Faculty of Education, Indonesia University of Education, year 2016. In this research, ML and AH became cases where both of them are the parents of the children with special needs in early age. The result toward the case shows that the parents have already understood their children's ability and inability but they have not understood their special needs and how to fulfill it. Then the result is they tend to worried and nervous even confused in treating their children related to take them care, their school, and they future. Whereas, the behavior, attitude and some efforts that appear along this time are not productive and harmony enough with their children's special need even with the demand of their selves and environment, so it does not give significant effect for the children's improvement and the decreasing parenting stress. However, even the obstacle learning and their children development are complex, but the parents are still optimist and they hope that one day, their children will growth as the normal children. According to that problems, the formula of the model family counseling to early age which is appropriate in reducing parenting stress that are facing by family with special needs children is the model that design by differentiating service by create interpersonal relationship, early intervention setting, group family support service, and home visit as the major pillar, is conducted by interdisciplinary approach and the expert as social support, and counselor's responsibility as an ahead and coordinator of all given counseling service program. In fact, this model is still hypotetic, so to test its effectiveness have to be tested further.
\end{abstract}

Key words: counseling, intervention, family

One of the main problem tends to be faced by parents of children with special needs is parenting system whereas the appearing of over worried and nervous related of take care and education of children with special needs. Primary when their children are in early age, this problem can be felt much more. This condition shows that since the parents of children with special needs need support through every service, they should avoid from parenting stress. It is believed that the service they need is family counseling service. This service will touch the basic problems that faced by parents comprehensively. In other way, remembering that the problem they are faced is complex, so the family counseling service have to integrate other relevant services appropriate with the needs of their children. One of the services has to be an integral part of family counseling service is a service of early intervention. It is because this service has a strategic position to reduce some learning difficulties and development of children with special needs. Connard and Novick (1996) stated that early intervention is a preventing program to reduce negative effect from other differences and to give big opportunity in order to reach healthy and optimal development.

Karoly et al. (2006) explicitly stated those early intervention programs are able to (1) improve the children's emotional and cognitive, usually in short term or to improve the relation of parents-children, (2) improve the process and result of children's education (3) improve the security financial, firstly is for parents, then for their children through bigger participation in job, and to increase their salary and prosperity, (4) decrease the criminals, and (5) improve the indicator related to children's health.

The essential part of early intervention setting is to help children and family. It means that the target of early intervention setting is not only for children, but also their family. Family has to be an integral part of all process and the implementation of early intervention setting. This problem is getting along with the practice of early intervention setting today. It is explained by Moore (2005) that along with this social exchanges and the development of early intervention, today it's practice has experienced some tendency exchanges, such as (1) from professional practice to focus on family (2) from focusing on children to focus on family 
(3) from isolation model to systemic ecologist system (4) from casual linier model to transaction model which is more complex (5) from multidisciplinary team to interdisciplinary team (6) from service that based on segregation service to the services that based on inclusive society. In ecology dimension, the attitudes of human being are the result of their social context, namely the result of dynamic interaction process between children and environment, primarily family as system Because of that, family is the most crucial development ecology. Bronfenbrenner (Apter, 1982) stated that family is the first altar for children. If children have good action in family, then they will get into another part of life easily. Family is "critical system", a place where the children learn how to satisfy their needs and how to face the world.

In same way, Connard and Novick (1996) stated that model of ecology is a family-centered approach. The main principle is the whole growth and development of children take place in a relation between them and their family. According to that problem, the comprehension toward learning difficulties and children with special needs development has to conduct through appreciation towards their family. Then the consequences is, this intervention have to place parents as its main focus. Early intervention setting has to be seen as a process to help family in solving some problems faced by children as subsystem of family. It is same with the statement, Individual with Disabilities Education Act Amendement (IDEA) years 1997 which is say that parents is a focus in improving children's communication, cognitive, social, emotional, and motorist development. This message shows the importance of relationship between parents and counselor in facilitating children's development (Watson, 2000).

Besides, basically counseling or family therapy is much more than a therapeutic technique, but it is a comprehensive approach to understand human's behavior. Family counseling not only can be applied in family context, but it can be applied in school when problem that faced by students related to the family. The essence of family counseling is to solve humanity problems that appear in the middle of family or being faced by individual as members of family, which disturb their life or the happiness of family life.

The basic essence of family counseling is an attempt to help the members of family who get problem.

According to the explanation above, parents need an effective family counseling approach to solve parenting stress, to be able to develop pragmatic techniques that needed in serving their children's special needs through social support development in order solve their problems. To formulate the model above, the focus of this research is, how is the empirical condition of family with children with special needs in early age and how effective is the model of family counseling in solving parenting stress faced by parents in early age?

To reach that aim, some data as an empirical condition is needed, such as (1) objective condition about the understanding of the parents of children with special needs in early age toward ability and their children's needs, (2) the problem they are facing (3) attitudes and behavior of parents toward their children (4) some efforts and its result (5) hopes toward their children. Then those data will be an empirical basic of counseling and it will be formulated.

\section{METHOD}

To gain an objective, accurate, and valid data, then this research is conducted by two approaches of qualitative study by using variation background. Those main backgrounds are in family context and in therapy clinic. Through those different observations, hopefully it will give accurate sketch of their problems and needs. The researcher as the research instrument, collecting data is conducted by observation, interviewing, and studying of documentation. The collected data is described in detail in form of report and explanation, then it's the meaning can be found. According to this problem, then this research is categorized as qualitative research.

The subject of this research is the parents of special needs children who are following early intervention program in Laboratory of Special Education Department -Faculty of Education - Indonesia University of Education year 2016, namely ML and AH.

\section{FINDINGS AND DISCUSSION}

\section{Findings}

\section{Case I (ML)}

ML is a mother of six children. One of his her children is Noval (3 years) a down syndrome person. In daily life, ML have no a permanent job, and her husband has passed away about one year ago.

Generaly, ML have a good understanding in knowing her child's ability and inability. She knows that her child has a slowly development, but she does not understand about what her child need is and how to fulfill it in case. In other way, in her point of view, Noval is "nice" child, he has never cried even when he is sick.

Sometimes ML feel sad, frustrated, unpredictable and pasrah. She also know that her husband has passed away and her economic condition is inadequate. Noval has ever been lived with her sister-in-law for several moths because his mother has that economic problem 
and other activities.

In other way, ML is not really pay attention to her children. ML tends to Noval alone, she never communicate with him even playing with him. She only interact and communicate with him when she feed him.

The main problems that faced by ML right now is she does not understand enough about what she has to treat her child to develop well. She does not has enough information about what kind of service she needs and where she can get it. Physicologically, sometimes ML feel worried, affraid, even stress, especially in taking her child care, schooling and her child's future. Her condition is more emphasized when she aware that her husband has passed away when Noval is very small child and really need him.

In her social live, ML is known as an unfriendly woman. It is may caused by her own attitudes because she usually get angry of her children. Because of that, ML never ask Noval to go outside even to go to the Posyandu. Her own motivation come from her brothers and sisters even her sisters-in-law sometimes treat Noval as her own son.

ML has never done specific effort toward her child so far, except ask him to see the doctor when he is sick.. Noval has never joined in development theraphy program at all. She only teach her other children to understand the condition of their brother to love and take him care. Because of those condition, Noval does not experience significant development.

ML are aware about her child's condition and it makes ML did not counting on her children. She is still optimistic and she hopes there is a miracle. Her bigger hopes right now is to see Noval walk, run, and play with his friends. Furthermore she hopes that Noval can school and stand on his own feet in the future.

\section{Case II (AH)}

AH is parent of Hikmal, a child with special needs, he has difficulties development in speaking and now he schools in Play Group. AH is a diver of a family with her main job is to accompany and pick the children of his boss up. Where NN, his wife is a house-wife.. Therefore Hikmal interact and communicate much more with her mother.

The awareness of AH as parent towards the ability of his child come previously. He knows that Hilmal is difficult in speaking. This condition is different with her normal elder sister.

The condition of Hikmal who has difficulties in speaking make AH difficult in understanding his needs. He is not only has difficulties in understanding his child, $\mathrm{AH}$ only has difficulties in telling, giving information or teach something to him.

In daily live, Hikmal actually is an active child, even cannot be quiet and easy to make friends. He does not embarrassed when meet his people. However, he tends to avoid talking with his friend. When people talk to him, he does not has an eye contact and avoid them.

In treating their child, $\mathrm{AH}$ and his wife tend to give everything he want. When hikmal want something by crying, his parents just give another alternative to make him quiet. Its because Hikmal has never deliver what he want by orally, except by crying, so his parent do not know what does he mean.

The main problem that faced by $\mathrm{AH}$ is the difficulties in communicating and interacting with his child. When he ask Hikmal to speak, he does not listen to him, he does not pay attention when his parent is teaching him, he rejects some asking and he tends to crying in asking everything. $\mathrm{AH}$ understand the condition of his child, but he does not know why it is happen and hoe to treat his child. Physiologically, AH is sad and confused of condition of Hikmal, even he feel frustrated because he think that his child does not need him. Socially, AH tends to limit the association of his child in order to avoid some negative reactions from his environment.

So far AH has never done some special effort in case asking help to the experts. He has ever asking Hikmal to "paranormal", but it is the request of the parent of AH. In contrast, in daily life, he only speak to him, but the result is not significant. Hikmal tends to use his physical movement to communicate than his language.

In treating his child, $\mathrm{AH}$ has big hope if his child could "be normal". AH hopes that Hikmal can speak and clearly and do communication. He wants Hikmal speak when he want something, does not cry anymore and stand on his feet. Therefore his child could develop normally, going to school, learning, make friends, and play together with friends as another children.

\section{Discussion}

The result of this research shows that children with special needs in the midle of family tend to create some physicology crises mainly related to the worried in taking care, schooling, and educate them (parenitng stress). The level is different, it is depends on the affected factor mainly their mental condition and the information they have. According to parents' point of view toward the ability and special needs of his child, some tendencies appear that parents understand their children's potencies, difficulties, weaknesses. But they do not understand enough the special needs of their child and how to fulfill it. In other side, parents have 
to give love and protection to their children. In some cases, the protection and love can be either positive or negative where it will be give bad development to their children. In other way, their children tend to affect the interaction process both internal and external. Then the effect is, some problem related to physiology and social condition appears. Meanwhile, Dunst and Trivette (Marfo, 1988) stated that behavior and development of children with special needs is affected by their families, healthy, mainly the interaction process of children and their parents. Besides, the function of each family members depend on the counselor as "social support". Ogden and Lipsett (1982) stated that the awareness of parents toward their children disability will create variation responds, mostly from negative to positive. The successful of parents through that respond depend on information and guidance they got from the counselor.

According to those problems, it needs a model of family counseling which is appropriate and comprehensive according to the problems they are facing. One of the models is by integrating familycentered approach in early intervention service as the important elements of the whole program of family counseling. It is believed that through this early intervention setting by teaching art and competencies to the parents will give good effect in interaction between parents and children, so it creates better learning ability than in another intervention steps liter on (Marfo, 1988).

\section{The Model of Family Counseling in Early Intervention Setting for Children with Special Needs.}

According to empirical and theoritical explanation above, it is concluded that the model of family counseling to reduce parenting stress are: (1) Parents as an central elements that have to be concerned in all counseling program; (2)Doing by miltidiscipliner team and counselor as the coordinator from all services program; (3) Doing by special programs that able to access the strenghs and weaknesess of child or characteristic and their needs; (4) Conducting counseling interviwe, early intervention setting, supporting parents group, and home visiting as the main program of all counseling programs.

From the explanation above, the model of family counseling for the parents of children with special needs is the model that are able to: (1) Place a high achievement toward parents as a privat totallity with their strengths and weaknesess; (2) Reach the basic problems that are faced by parents or children.; (3) Involve another expert in transdiscipliner team; (4) Place the early intervention setting, the group of parents, and home visiting as the main programs of counseling programs; (5) Place counselor as the main program of family counseling program.

\section{Model orientation}

This model is addressed to parents of children with special needs in early age, and to reduce parenting tress and it id done trough teamwork and transdiscipliner team. The model is developed by two main bases, namely: (1) empirical base; the result of this research, (2) conceptual base; the theoritical study about the family counseling for parents of children with special needs in early age.

In this aproach, all of the counseling programs have to be based on the special needs of family as the educate individual. It means that parents have to be a central elements to be concerned but it does not mean have to be specialisized. It has to be adjusted by the condition that they have good potencies to solve both their own problems and problems related to their children with special needs children, in order to show a family with characteristic and unique problems which is different with normal family.

Therefore the counseling program that is developing will be able to have a wider spectrum so it can reach the basic problems faced by both parents and children. The consequencies are, job's counselor is not only as an family relation, but it has to create the wider and variation situation. It will be able to formulate and manage more complex counseling program whether from its approach, activities, technique, and the expert.

\section{Program}

To reach the whole basic problems that are facing by children with special needs parents, so this counseling programs have to has a wider spectrum with the counselor as the major actor. Through this program, hopefully they are able to reflect or accsess characteristic and their basic needs comprehensively..

\section{Role of Counselor}

According to the progaram have been formulated before, the main roles of the counselor are: (1) To be able to conduct counseling interview as the main point of all family counseling programs; (2) To be able to do some assessment to know the first condition of parents and children and to communicate it to the related expert; (3) To be able to plan, formulate, and manage the counseling program which is differentiates according to parents's and children's need; (4) To be able to be a mediator, facilitator, catalisator, and motivator to reach the whole counseling program in order to reach all of the targetted aim; (5) To be able to be a coordinator and work together harmoniously with transdiscipliner team; (6) To be able to conduct individual counseling which is appropriate with the unique problems that are facing by parents; (7) To be 
able to make an interpersonal relation with parents as the main program of all counseling programs; (8) To be able to be a teacher of social skill and another life skills and to develop an agreement in order to fulfill their children's need.

\section{CONCLUSION AND SUGGESTION}

There are similarities between family who has children with special needs. Those similarities are the appearing of worried and affraid related to parenting stress. To face that problems, the model of family counseling of early intervention setting really help to reduce parenting stress which is faced by children with special needs family is family centered approach, designed by differentiation services and interpersonal relation, early intervention setting, group service, and home visiting as its main pilar is conducted through transdiscipliner approach, and counselor's responsibility as sosial support and the coordinator of all counseling programs.

\section{REFERENCE}

Apter, J. (1982). Trouble System, Trouble Children. New York: Prentice Hall Inc.

Connard, N., \& Novick, R. (1996). The Ecology of The Family: A Background Paper for a Family Centered Approach to Education and Social Service Delivery. Retrieved August 28, 2015, from http://www.nwrel.org/cfc/publica-tions/ ecology $2 . h t m l$

Karoly, L. A., Kilburn, M. R., \& Cannon, J. S. (2006). Early childhood interventions: Proven results, future promise. Rand Corporation.

Moore, T. (2005). Evolution of Early Childhood Intervention Practice, Victoria: Centre for Community Child Health, Murdoch Children's Research Centre,

Watson. (2000). Hand book of Language Impairment in Children: Assessment and Treatment, Canada: Delmar Thomson Learning. 